\title{
Quality of life among dually diagnosed and non-substance-using male schizophrenia outpatients
}

\author{
H I Aras, ${ }^{1} \mathrm{MD}$; M S Yazar, ${ }^{2} \mathrm{MD}$; K Altınbaş, ${ }^{3} \mathrm{MD}$ \\ ${ }^{1}$ Iğdır State Hospital, Department of Psychiatry, Iğdır, Turkey \\ ${ }^{2}$ Bakırköy Research and Training Hospital, Department of Psychiatry, Istanbul, Turkey \\ ${ }^{3}$ Çanakkale Onsekiz Mart University Faculty of Medicine, Department of Psychiatry, Çanakkale, Turkey
}

Corresponding author: H I Aras (ipekimer@hotmail.com)

\begin{abstract}
Objective. To assess the quality of life (QoL) in an outpatient setting among male patients dually diagnosed with schizophrenia and substance use disorder (SUD), and non-substance-using male schizophrenia patients.

Methods. The study was conducted in an outpatient setting with 52 male schizophrenia patients and 49 male schizophrenia patients with SUD comorbidity, who were admitted to Bakirköy Research and Training Hospital between 1 May 2010 and 30 September 2010. The patients had been in remission for a minimum of 6 months. The subjects were re-evaluated for the persistence of the diagnosis by using the Structural Clinical Interview for DSM-IV Axis I disorders (SCID I) socio-demographic data form, and the World Health Organization Quality of Life Scale Brief Version (WHOQOL-BREF) and positive and negative syndrome scale (PANSS) were administered to detect the factors affecting diagnostic stability and clinical course.

Results. Schizophrenia patients with no SUD comorbidity had a significantly earlier age of disease onset than the comorbid group. SUD comorbidity in schizophrenia patients leads to increased rates of unemployment and homicidality. WHOQOL-Bref psychological health scores were significantly lower among patients in the comorbidity group. No statistically significant difference was identified between the groups with regard to the PANSS scores.

Conclusions. It is necessary to focus on the treatment challenges for schizophrenia patients with SUD comorbidity, such as the provision of treatment in criminal justice settings, in which a high proportion of such patients are found.
\end{abstract}

S Afr J Psych 2013;19(2):35-39. DOI:10.7196/SAJP.416

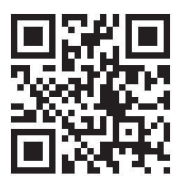

Clinical and epidemiological studies have reported up to $47 \%$ substance-use disorder (SUD) comorbidity in patients with schizophrenia. ${ }^{[1]}$ Addressing SUD comorbidity is clinically relevant since it has a significant impact on the course and prognosis of schizophrenia. For example, it can lead to acute bouts of hospitalisation by reducing patient compliance with antipsychotic treatment. ${ }^{[2]}$ Among psychiatric patients, particularly ones with schizophrenia, comorbidity has been associated with more frequent emergency room visits, criminality, violence, increased fluctuation and severity of psychiatric symptoms, legal problems and family stress. ${ }^{[3-5]}$

Aside from the pharmacological treatments used for reducing symptoms, researchers have started to place greater importance on patient satisfaction, treatment assessment by the patient, and patients' subjective well-being in the last few years. Thus, researchers' emphasis on evaluating and enhancing quality of life (QoL) in patients with schizophrenia is gradually increasing. ${ }^{[6-8]}$ The World Health Organization Quality of Life Scale Brief Version scale (WHOQOLBREF) assesses individuals' self-perception of their position in life within the context of the culture and value systems in which they live, and in relation to their goals, expectations and concerns. ${ }^{[9-11]}$
Few studies describing the QoL of schizophrenia patients have been published to date, and even fewer have compared the QoL of schizophrenia patients with and without SUD comorbidity. Two studies examining the effects of SUD on schizophrenia outpatients identified significantly lower QoL scores in the comorbid group, ${ }^{[12,13]}$ but the paucity of such studies indicates that this question is still under-explored and merits further investigation. Furthermore, there is very little information in Turkey regarding the QoL of the patients with both schizophrenia and SUD.

In this study, we aimed to assess the QoL of patients dually diagnosed with schizophrenia and SUD, and in non-substance-using male schizophrenia outpatients. It was assumed that due to the neurotoxic, physical and medical effects engendered by substance use, the comorbid group would report poorer QoL scores than schizophrenia patients with no SUD.

\section{Methods and patient characteristics}

The study was conducted among 101 schizophrenia patients, of whom 52 (51.8\%) were non-comorbid and 49 (48.52\%) had SUD comorbidity. All patients had been previously discharged from hospital and had been in remission for a minimum of 6 months. 
All patients satisfied the Diagnostic and Statistical Manual of Mental Disorders IV (DSM-IV) criteria for schizophrenia, and schizophrenia with SUD comorbidity. ${ }^{[14]}$

Subjects were excluded if they did not meet these criteria, or if they had any of the following: $(i)$ evidence of organic central nervous system disorder; (ii) age $<18$ or $>65$ years; (iii) mental retardation. The study was described to the patients both verbally and in writing, and signed informed consent was obtained from each subject.

The information concerning sociodemographic variables was collected using the Past History and Sociodemographic Data Form, which records information regarding the patient's level of education, employment status, family and residence. The positive and negative syndrome scale (PANSS) was used to ascertain whether the severity of illness differed between the two groups. ${ }^{[15]}$ Differences between the groups' perception of their QoL were determined by analysis of the WHOQOL-BREF scales. The assessment of QoL included 4 aspects: physical, psychological, social and enviromental. ${ }^{[16]}$

\section{Statistical analysis}

Data were analysed using SPSS software. The data were assessed using descriptive statistical processes such as standard deviations (SDs) and means. In addition, chi-square and Fisher's exact tests were used to compare the rate and frequency of categorical variables. Means of continuous variables in the two groups were compared with Student's $t$-test. Furthermore, the Kruskal-Wallis and Mann-Whitney U tests were used when the parametric assumption was not achieved, and the Spearmen's rank Correlation Analysis was also used. In addition, except where the parametric assumption was not achieved, the Pearson correlation was used for the correlation analyses. Results with $p<0.05$ were considered statistically significant.

\section{Results}

The average age of the participants was 32 years, and the average educational level was 8.80 years $(\mathrm{SD} \pm 3.42)$ in comorbid patients and 9.67 years $(\mathrm{SD} \pm 3.34)$ in non-comorbid patients. Most subjects were single and lived alone. The types of substances used are presented in Table 1; the most common was alcohol and cannabis in combination, used (16; 32.6\%), followed by alcohol alone (9; $18.3 \%)$.

Non-comorbid patients had a significantly earlier age of disease onset than the comorbid group. The average age of disease onset among non-comorbid patients was 20.52 years (SD \pm 4.52 ), and the average total number of hospitalisations was 4.36 years (SD \pm 5.60 ). In the comorbid group, the average age at onset was 23.12 years $(\mathrm{SD} \pm 5.49)$ and the average total number of hospitalisations was 4.90 years $(\mathrm{SD} \pm 5.13$ ). The difference between the number of hospitalisations of the two groups was not found to be statistically significant $(p>0.05)$.

However, the differences in the employment status of the two groups were found to be statistically significant $(p=0.039)$, as were the differences in the antipsychotic treatment modalities $(p<0.05)$. In other words, non-substance-using schizophrenia patients demonstrated significantly higher levels of employment and used their combination of antipsychotic treatments more frequently. Another statistically significant difference was that the comorbid group displayed higher levels of homicide attempts $(p<0.05)$ and criminality $(p<0.01)$ than non-substance-using patients.

Table 2 shows the PANSS severity scores of the two groups. There were no significant differences between the two groups.

Table 3 demonstrates the statistically significant difference between the two groups' evaluation of the psychological aspect of their QoL (according to the WHOQOLBREF). Non-substance-using patients had higher levels of satisfaction than patients with SUD comorbidity $(p<0.05)$. No statistically significant differences were identified between the two groups' assessment of physical health, social relationships and environmental QoL.

To investigate whether and how the changes in QoL were related to changes in psychopathology, we correlated the WHOQOL-BREF domain scores with the PANSS scores (the results are presented on Tables 4 and 5).

Table 4 indicates the descriptive statistics for the WHOQOL-BREF and PANSS scores of patients with SUD comorbidity. It was demonstrated that, when levels of symptom

Table 1. Categories of substances used

\begin{tabular}{ll}
\hline Substances used $(\mathbf{N = 4 9 )}$ & $\boldsymbol{n}(\%)$ \\
\hline Alcohol & $9(18.3)$ \\
Cannabis & $6(12.2)$ \\
Inhalants & $2(4.1)$ \\
Others & $5(10.2)$ \\
Alcohol and cannabis & $16(32.6)$ \\
Alcohol and inhalants & $2(4.1)$ \\
Cannabis and inhalants & $4(8.1)$ \\
Cannabis and others & $2(4.1)$ \\
Alcohol, cannabis and inhalants & $3(6.1)$
\end{tabular}

Table 2. Descriptive statistics of PANSS scores of the two groups ${ }^{\star}$

\begin{tabular}{|c|c|c|c|}
\hline \multirow[b]{2}{*}{ PANSS } & \multicolumn{2}{|c|}{ Schizophrenia patients $(N=101)$} & \multirow[b]{2}{*}{$p$-value } \\
\hline & $\begin{array}{l}\text { No comorbid substance-use disorder }(N=52) \\
\text { mean }( \pm \mathrm{SD})\end{array}$ & $\begin{array}{l}\text { Comorbid substance-use disorder }(N=49) \\
\text { mean }( \pm \mathrm{SD})\end{array}$ & \\
\hline Positive & $9.19( \pm 3.15)$ & $10.20( \pm 4.31)$ & 0.230 \\
\hline Negative & $11.23( \pm 5.67)$ & $11.81( \pm 6.76)$ & 0.815 \\
\hline General psychopathology & $19.05( \pm 6.83)$ & $19.32( \pm 4.75)$ & 0.298 \\
\hline Total & $39.48( \pm 11.96)$ & $41.34( \pm 13.78)$ & 0.461 \\
\hline
\end{tabular}


scores were rated lower, the QoL scores were rated higher. In other words, lower symptomatology was associated with higher QoL. Non-substance-using patients' PANSS positive symptoms $(p<0.01)$ and general psychopathological symptoms $(p<0.05)$ were correlated significantly and negatively with the WHOQOL-BREF physical health scores. PANSS positive symptoms and total scores were correlated significantly and negatively with the WHOQOL-BREF psychological health scores $(p<0.01)$. PANSS positive symptoms, negative symptoms, general psychopathological symptoms and total scores were correlated significantly and negatively with the WHOQOL-BREF social relationship scores $(p<0.01)$. PANSS positive symptoms, negative symptoms, general psychopathological symptoms $(p<0.05)$ and total scores $(p<0,01)$ were correlated significantly and negatively with the WHOQOL-BREF environmental QoL scores.

Table 5 indicates the descriptive statistics for the WHOQOL-BREF and PANSS scores of patients with SUD comorbidity. Comorbid patients' PANSS positive symptoms $(p<0.05)$, negative symptoms, general psychopathological symptoms and total scores $(p<0.01)$ correlated significantly and negatively with the WHOQOL-BREF social relationship scores. PANSS negative symptoms, general psychopathological symptoms $(p<0.01)$ and total scores $(p<0.05)$ correlated significantly and negatively with WHOQOL-BREF environmental QoL scores. PANSS positive symptoms, negative symptoms, general psychopathological symptoms and total scores did not correlate with the WHOQOL-BREF physical and psychological health scores $(p>0.05)$. PANSS positive symptoms did not correlate with the WHOQOL-BREF environmental QoL scores $(p>0.05)$.

\section{Discussion}

The study results revealed that the groups did not differ with respect to average age, educational level, marital status and the number of hospitalisations. This was not consistent with studies reporting that dual

Table 3. Descriptive statistics of WHOQOL-BREF scores of the two groups ${ }^{*}$

\begin{tabular}{|c|c|c|c|}
\hline \multirow[b]{2}{*}{ WHOQOL-BREF } & \multicolumn{2}{|c|}{ Schizophrenia patients $(N=101)$} & \multirow[b]{2}{*}{$p$-value } \\
\hline & $\begin{array}{l}\text { No comorbid SUD }(N=52) \\
\text { mean }( \pm S D)\end{array}$ & $\begin{array}{l}\text { Comorbid SUD }(N=49) \\
\text { mean }( \pm S D)\end{array}$ & \\
\hline Psychological health & $13.29( \pm 2.10)$ & $12.19( \pm 2.12)$ & $0.010^{\dagger}$ \\
\hline Social relationships & $10.64( \pm 4.20)$ & $10.58( \pm 3.11)$ & 0.939 \\
\hline
\end{tabular}

Table 4. Descriptive statistics of WHOQOL-BREF and PANSS measures of patients with no comorbid SUD (N=52)

\begin{tabular}{llll}
\hline & & \multicolumn{2}{c}{ WHOQOL-BREF } \\
\cline { 2 - 4 } PANSS & Physical health & Psychological health & Social relationships \\
\hline Positive & $-0.355^{*}$ & $-0.430^{*}$ & $-0.420^{*}$ \\
Negative & -0.043 & -0.200 & $-0.462^{*}$ \\
General psychopathology & $-0.315^{\dagger}$ & -0.242 & $-0.364^{*}$ \\
Total & -0.238 & $-0.357^{*}$ & $-0.540^{*}$ \\
Results are according to Spearman's rank-correlation analysis. PANSS $=$ positive and negative syndrome scale; WHOQOL-BREF $=$ The World Health Organization Quality of Life Scale Brief Version; \\
SUD $=$ substance-use disorder; QoL $=$ quality of life.
\end{tabular}

Table 5. Descriptive statistics of WHOQOL-BREF and PANSS measures of patients with comorbid SUD $(N=49)$

\begin{tabular}{|c|c|c|c|c|}
\hline \multirow[b]{2}{*}{ PANSS } & \multicolumn{4}{|c|}{ WHOQOL-BREF } \\
\hline & Physical health & Psychological health & Social relationships & Environmental QoL \\
\hline Positive & -0.044 & -0.146 & $-0.297^{\dagger}$ & -0.276 \\
\hline Negative & -0.177 & -0.170 & $-0.474^{*}$ & $-0.369^{*}$ \\
\hline General psychopathology & -0.193 & -0.164 & $-0.401^{*}$ & $-0.382^{*}$ \\
\hline Total & -0.124 & -0.171 & $-0.452^{*}$ & $-0.330^{\dagger}$ \\
\hline
\end{tabular}


diagnosis is associated with younger age, single status, lower educational level and more frequent hospitalisations. ${ }^{[17-21]}$ Schizophrenia patients with no SUD comorbidity showed significantly higher levels of employment, which is consistent with most of the studies in the literature. ${ }^{[20-22]}$

Substance use is thought to impair occupational activities and function. The primary substances used were alcohol and cannabis. This is typical of other population studies, which indicate that schizophrenia patients prefer drugs that are easier to obtain. Furthermore, the differences in lifetime consumption of certain drugs might be the result of lower social skills and decreased ability to procure certain illicit drugs. ${ }^{[22]}$ Additionally, recent work on individuals' potential biological vulnerability to cannabis might explain the observed variance in the risk of later-developing schizophrenia. This again raises the possibility that the clinical associations that we commonly observe in schizophrenia may have biological and potentially aetiopathological significance. ${ }^{[5]}$

Non-comorbid patients had a significantly earlier age of disease onset than the comorbid group. This contradicts the findings of some firstepisode studies, which indicate earlier ages of onset for individuals with a history of comorbid substance use. ${ }^{[23-28]}$ However, not all studies have shown this. ${ }^{[29-32]}$ One explanation for the earlier age of onset of psychosis in comorbid patients is that the illness is precipitated by substance use. It nevertheless remains uncertain whether this effect is limited to people with a predisposition to psychosis. ${ }^{[33,34]}$ Another possible explanation is that the early onset of symptoms is a risk factor for substance use. ${ }^{[13,35,36]}$ Previous studies explored these hypotheses by examining the temporal relationship between the onset of schizophrenia and substance use. The findings have been mostly inconsistent, ${ }^{[35-37]}$ and, in general, have only addressed the relationship between substance use and the onset of psychotic symptoms, and not the possible relevance of prodromal symptoms. Furthermore, the relatively high proportion of patients who reported lifetime substance use in this and other studies raises the possibility that substance-related symptoms could confound retrospective estimation of onset age. For example, druginduced phenomena may be mistaken for early symptoms of illness, or substance use may mask psychotic symptoms. ${ }^{[38]}$ In the latter situation, if patients perceive their early psychotic symptoms to be drug-induced, this may delay their request for help and medical assistance. Norman et al. ${ }^{[39]}$ propose more generally that substance use by people with psychosis may partly reflect denial of the severity of their illness and of the potential benefit of medical intervention, and may thus be associated with a reduced likelihood of seeking treatment soon after the onset of psychosis. Our findings may support such a view, in that we found schizophrenia patients with no SUD comorbidity to have a significantly earlier age of disease onset than comorbid patients.

A statistically significant difference between the two groups was the higher levels of homicide attempts and criminality among comorbid patients. Swinson et al. ${ }^{[40]}$ suggest that there is an increase in drug and alcohol misuse among people with schizophrenia who committed homicide; however, they did not establish any causality to support this claim. A study of 49 homicidal schizophrenia patients reported that $24.5 \%$ were using alcohol while $4.1 \%$ used cannabis. ${ }^{[41]}$ Nevertheless, Bennet et al..$^{[42]}$ contend that the association between homicidal violence and schizophrenia cannot be explained simply on the basis of comorbid substance abuse.
In our study, there were no differences between the groups with regard to negative symptoms, positive symptoms and general psychopathology. Addington and Addington ${ }^{[12]}$ had compatible results in terms of negative symptoms, and found that patients with comorbidity had higher PANSS positive symptoms. In turn, Talamo et al. ${ }^{[43]}$ described higher PANSS positive and lower PANSS negative scores in schizophrenia patients with comorbidity, which is also not compatible with our study. Nevertheless, such results are not surprising, as the literature suggests that SUD comorbidity in schizophrenia patients will likely lead to an increase in positive symptoms. ${ }^{[44]}$

Our study results support the hypothesis that schizophrenia patients with SUD comorbidity will report poorer QoL scores than noncomorbid patients. There are at least 3 potential explanations for this: - It is possible that these patients are functioning at a lower level in their interpersonal relationships than non-substance-using patients.

- Comorbidity has negative social impacts in schizophrenia patients. The dually diagnosed patients are more prone to stress associated with the daily struggles for survival (such as being exposed to violence and other harms).

- It is possible that non-substance-using schizophrenia patients may have developed better coping and self-management skills over the course of their illness, as well as a greater acceptance of the illness and compliance with treatment. The more frequent use of antipsychotic treatment combinations observed in our study may be the result of their greater level of treatment acceptance.

Patients with schizophrenia who have SUD comorbidity may actually have milder symptoms. Their poorer course is more attributable to the direct effect of drugs on the worsening symptoms, the greater propensity to antipsychotic-related side-effects, and associated medication non-compliance. ${ }^{[17]}$ Similar to the results of our current study, dually diagnosed patients in two studies by Addington and Addington ${ }^{[12,13]}$ had significantly lower QoL scores than nonsubstance-using patients with schizophrenia. Contrary to our results, dual-diagnosis patients in the study of Herman et al. ${ }^{[44]}$ expressed higher levels of satisfaction with their QoL compared with noncomorbid patients. This inconsistency could be related to several factors, such as differences in the samples and the selected QoL measures (WHOQOL-BREF v. the Quality of Life Scale).

\section{Study limitations}

Our results relate to a study population from inner Istanbul, and may not be generalised confidently to populations from suburban or rural areas. The self-reporting nature of the QoL scale used was a potential source of bias, as there may be a lack of awareness as well as a misrepresentation of the symptoms on the patients' part. ${ }^{[45]}$ As observed in the general population, ${ }^{[46]}$ individuals with mental illnesses may selectively under-report the recent misuse of some drugs to their families, health professionals and researchers. This is unfortunate, since the consequences of misuse of these various substances would be expected to differ considerably.

\section{Conclusions and implications for interventions}

In summary, SUD comorbidity in schizophrenia leads to higher rates of unemployment and homicidality among patients. It is necessary to 


\section{$n$
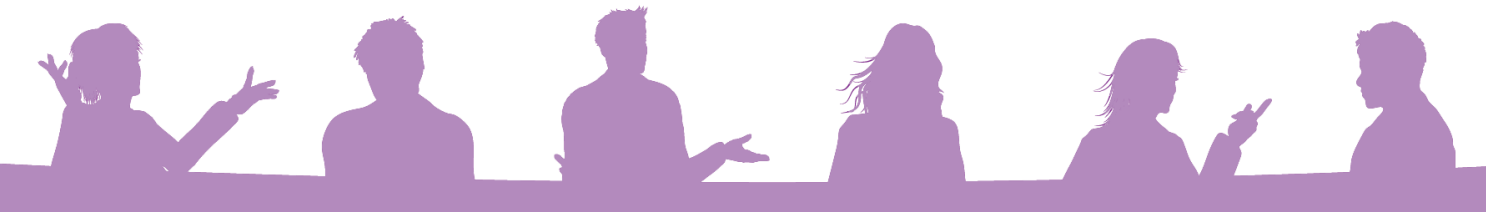

focus on the treatment challenges for comorbid patients, such as the provision of treatment in criminal justice settings, in which a high proportion of such patients are found..$^{[4]}$

\section{References}

1. Verma SK, Subramaniam M, Chong SA, Kua EH. Substance abuse in schizophrenia: A Singapore perspective. Soc Psychiatry Psychiatr Epidemiol 2002;37(7):326-328. [http://dx.doi org/10.1007/s00127-002-0553-8]

2. Schmidt LM, Hesse M, Lykke J. The impact of substance use disorders on the course of schizophrenia - a 15-year follow-up study: Dual diagnosis over 15 years. Schizophr Re 2011;130(1-3):228-233. [http://dx.doi.org/10.1016/j.schres.2011.04.011]

3. Bartels SJ, Teague GB, Drake RE, et al. Substance abuse in schizophrenia: Service utilization and costs. J Nerv Ment Dis 1993;181(4):227-232.

4. Bergman HC, Harris M. Substance abuse among young adult chronic patients. Psychosocl Rehabil J 1985;9(1):49-54.

5. Buckley PF, Brown ES. Prevalence and consequences of dual diagnosis. J Clin Psychiatry 2006;67(7):e01.

6. Meltzer HY. Outcome in schizophrenia: Beyond symptom reduction. J Clin Psychiatry 1999;60:3-7.

7. Woon PS, Chia MY, Chan WY, Sim K. Neurocognitive, clinical and functional correlates of subjective quality of life in Asian outpatients with schizophrenia. Prog Neuropsychopharmacol Biol Psychiatry 2010;34(3):463-468. [http://dx.doi.org/10.1016/j.pnpbp.2010.01.014]

8. Katschnig H. Schizophrenia and quality of life. Acta Psychiatr Scand 2000;102(407):33-37. [http://dx.doi.org/10.1034/j.1600-0447.2000.00006.x]

9. Fidaner H, Elbi H, Fidaner C, et al. Yaşam kalitesinin ölçülmesi, WHOQOL-100 ve WHOQOL-BREF. 3p Dergisi 1997;7(Ek 2):3-66.

10. Bullinger M, Hasford J. Evaluating quality of life measures for clinical trials in Germany. Control Clin Trials 1991;12:91-105.

11. Angermeyer MC, Killian R. Theoretical models of quality of life in mental disorders. In: Katsching H, Freeman H, Sartorius N, eds. Quality of life in mental disorders. New York: Wiley, 1997:112-117.

12. Addington J, Addington D. Substance abuse and cognitive functioning in schizophrenia. J Psychiatry Neurosci 1997;22(2):99-104.

13. Addington J, Addington D. Effects of substance misuse in early psychosis. Br J Psychiatr Suppl 1998;172(33):134-136.

14. American Psychiatric Association. Diagnostic and Statistical Manual of Mental Disorders. 4th ed. Arlington, USA: American Psychiatric Association, 2000.

15. Kay SR, Fizbein A, Opler LA. The Positive and Negative Syndrome Scale (PANSS) for schizophrenia. Schizophr Bull 1987;13(2):261-276.

16. Murphy B, Herrman H, Hawthorne G, Pinzone T, Evert H. Australian WHOQOL instruments: Users' Manual and Interpretation Guide. Melbourne, Australia: Australian WHOQOL Field Study Centre, 2000.

17. Dixon L. Dual diagnosis of substance abuse in schizophrenia: Prevalence and impact on outcomes. Schizophr Res 1999;35:S93-S100.

18. Mueser KT, Yarnold PR, Rosenberg SD, et al. Substance use disorder in hospitalized severely mentally ill psychiatric patients: Prevalence, correlates, and subgroups. Schizophrenia Bull 2000;26(1):179-192.

19. Duke PJ, Pantelis C, McPhillips MA, Barnes TR. Comorbid non-alcohol substance misuse among people with schizophrenia: Epidemiological study in central London. Br J Psychiatry 2001;179:509-513.

20. Fowler IL, Carr VJ, Carter NT, Lewin TJ. Patterns of current and lifetime substance use in schizophrenia. Schizophr Bull 1998;24(3):443-455.

21. Mueser KT, Yarnold PR, Levinson DF, et al. Prevalence of substance abuse in schizophrenia: Demographic and clinical correlates. Schizophr Bull 1990;16(1):31-56

22. Volkow ND. Substance use disorders in schizophrenia - clinical implications of comorbidity Schizophrenia Bulletin 2009;35(3):469-472. [http://dx.doi.org/10.1093/schbul/sbp016]

23. Rabinowitz J, Bromet EJ, Lavelle J, et al. Prevalence and severity of substance use disorders and onset of psychosis in first-admission psychotic patients. Psychol Med 1998;28(6):1411-1419.
24. Van Mastrigt SV, Addington J, Addington D. Substance misuse at presentation to an early psychosis program. Soc Psychiatry Psychiatr Epidemiol 2004;39(1):69-72. [http://dx.doi. org/10.1007/s00127-004-0713-0]

25. Veen ND, Selten JP, van der Tweel I, et al. Cannabis use and age at onset of schizophrenia. Am J Psych 2004;161(3):501-506

26. Mathers DC, Ghodse AH, Caan AW, Scott SA. Cannabis use in a large sample of acute psychiatric admissions. Br J Addict 1991;86(6):779-784.

27. Bersani G, Orlandi V, Kotzalidis GD, Pancheri P. Cannabis and schizophrenia: Impact on onset, course, psychopathology and outcomes. Eur Arch Psychiatry Clin Neurosci 2002;252(2):86-92. [http://dx.doi.org/10.1007/s00406-002-0366-5]

28. Veen N, Selten JP, Hoek HW, et al. Use of illicit substances in a psychosis incidence cohort: A comparison among different ethnic groups in the Netherlands. Acta Psychiatr Scand 2002;105:440-443.

29. Cantor-Graae E, Nordström LG, McNeil TF. Substance abuse in schizophrenia: A review of the literature and a study of correlates in Sweden. Schizophr Res 2001;48(1):69-82.

30. Sevy S, Robinson DG, Solloway S, et al. Correlates of substance misuse in patients with firstepisode schizophrenia and schizoaffective disorder. Acta Psychiatr Scand 2001;104(5):367-374.

31. Peralta V, Cuesta MJ. Influence of cannabis abuse on schizophrenic psychopathology. Acta Psychiatr Scand 1992;85(2):127-130.

32. Sembhi S, Lee JW. Cannabis use in psychotic patients. Aust N Z J Psychiatry. 1999;33(4):529-532

33. Smit F, Bolier L, Cuijpers P. Cannabis use and the risk of later schizophrenia: A review. Addiction 2004;99(4):425-430. [http://dx.doi.org/10.1111/j.1360-0443.2004.00683.x]

34. Henquet C, Krabbendam L, Spauwen J, et al. Prospective cohort study of cannabis use, predisposition for psychosis and psychotic symptoms in young people. BMJ 2005;330(7481):11. [http://dx.doi.org/10.1136/bmj.38267.664086.63]

35. Hambrecht M, Häfner H. Substance abuse and the onset of schizophrenia. Biol Psychiatry 1996;40(11):1155-1163. [http://dx.doi.org/10.1016/S0006-3223(95)00609-5]

36. Degenhardt L, Hall W, Lynskey M. Testing hypotheses about the relationship between cannabis use and psychosis. Drug Alcohol Depend 2003;71(1):37-48.

37. Hambrecht $M$, Häfner $H$. Cannabis, vulnerability and the onset of schizophrenia: An epidemiological perspective. Aust N Z J Psychiatry 2000;34(3):468-475.

38. Larsen TK, McGlashan TH, Johannessen JO, et al. Shortened duration of untreated firs episode of psychosis: Changes in patient characteristics at treatment. Am J Psychiatry 2001;158(11):1917-1919.

39. Norman RMG, Malla Malla AK. Examining adherence to medication and substance use as possible confounds of duration of untreated psychosis. J Nerv Ment Dis 2002;190(5):331334.

40. Swinson N, Flynn SM, While D, et al. Trends in rates of mental illness in homicide perpetrators. Br J Psychiatry 2011;198(6):485-489. [http://dx.doi.org/10.1192/bjp.bp.110.085357]

41. Belli H, Özçetin H, Ertem U, et al. Perpetrators of homicide with schizophrenia: Sociodemographic characteristics and clinical factors in the eastern region of Turkey. Compr Psychiatry 2010;51(2):135-141. [http://dx.doi.org/10.1016/j.comppsych.2009.03.006]

42. Bennett DJ, Ogloff JR, Mullen PE, et al. Schizophrenia disorders, substance abuse and prior offending in a sequential series of 435 homicides. Acta Psychiatr Scand 2011;124(3):226-233. [http://dx.doi.org/10.1111/j.1600-0447.2011.01731.x]

43. Talamo A, Centorrino F, Tondo L, et al Comorbid substance-use in schizophrenia: Relation to positive and negative symptoms. Schizophr Res 2006;86(1-3):251-255. [http://dx.doi. org/10.1016/j.schres.2006.04.004]

44. Herman M. Neurocognitive functioning and quality of life among dually diagnosed and non-substance abusing schizophrenia inpatients. Int J Ment Health Nurs 2004;13(4):282-291. [http://dx.doi.org/10.1111/j.1440-0979.2004.00346.x]

45. Atkinson M, Zibin S, Chuang H. Characterizing quality of life among patients with chronic mental illness: A critical examination of the self-report methodology. Am J Psychiatry 1997;154(1):99-105.

46. Cook RF, Bernstein AD, Arrington TL, Andrews CM, Marshall GA. Methods for assesing drug use prevalence in the workplace: A comparison of self report, urinalysis, and hair analysis. Int J Addict 1995;30:403-426.

47. Belli H, Ural C. The association between schizophrenia and violent or homicidal behaviour: The prevention and treatment of violent behaviour in these patients. West Indian Med J 2012;61(5):538-543. 